\title{
Responses of the Human Upper Extremity Vascular Bed to Exercise, Cold, Levarterenol, Angiotensin, Hypertension, Heart Failure, and Respiratory Tract Infection with Fever *
}

\author{
L. J. Kettel, $\dagger$ H. W. Overbeck, $\$$ R. M. Daugherty, $\S$ J. P. Lillehei, $\|$ \\ R. F. Coburn, đI and F. J. Haddy $\S$ \\ (From the Veterans Administration Research Hospital, Chicago, Ill., and the Departments of \\ Physiology and Medicine, the Medical School, University of Minnesota, Minneapolis, \\ Minn., the Medical School, Northwestern University, Chicago, Ill., and the \\ University of Oklahoma Medical Center, Oklahoma City, Okla.)
}

Alterations of pressure, flow, and resistance to flow in peripheral vascular beds occur frequently and are often grave (5). Because of technical difficulties, however, pressure and flow are infrequently measured and resistance is rarely calculated. As a result, certain facets of the alterations continue to provoke controversy. The exact site of the increase in peripheral resistance in essential hypertension has not been established. Neither is there unanimity of opinion on the caliber of veins in congestive heart failure, extremity blood flow in respiratory tract infection with fever, or venous

* Submitted for publication November 27, 1963; accepted April 15, 1964.

Presented in part at the Symposium on Peripheral Vascular Disease, Rochester, Minn., September 23, 1957, the Midwest Regional Meeting of the American College of Physicians, Chicago, Ill., September 24, 1960, and the meeting of the Midwestern Section of the American Federation for Clinical Research, Chicago, Ill., October 31, 1963. Parts of the study formed the basis of a thesis (1) and appeared in abstract form (2-4). The investigation was supported in part by grants AI-03714, HE-062860, and HE-06759 from the U. S. Public Health Service and grant 62-G-16 from the American Heart Association.

† Work done during the tenure of a U. S. Public Health Service Traineeship, Cardiovascular Training Grant HTS-5334. Present address: Veterans Administration Research Hospital, Chicago, Ill.

$\ddagger$ Present address: Veterans Administration Hospital, Oklahoma City, Okla.

§ Present address: University of Oklahoma Medical Center, Oklahoma City, Okla.

|l Present address: University of Minnesota Medical School, Minneapolis, Minn.

I Present address: University of Pennsylvania, Graduate School of Medicine, Philadelphia, $\mathrm{Pa}$. resistance and capillary pressure after exposure to vasoconstrictor agents or cold.

Extremity blood flow can be measured by indicator dilution (6). A practical technique for measuring pressures in small blood vessels has been developed in animals (5, 7-9). In this study, the animal techniques were adapted to the human and combined with an indicator dilution method of measuring flow, thereby providing large and small vessel pressures, flow, and total and segmental vascular resistances in the human upper extremity. The techniques were then utilized to shed light on the above problems.

\section{Methods}

Pressures were measured at two, three, or four sites along the length of the upper extremity vascular bed. These sites included the brachial artery just above the elbow, the radial artery or one of its branches, a vein on the dorsum of the hand or proximal phalanx, and a vein in or near the antecubital space. Extremity blood flow was estimated by an indicator-dilution method.

Pressures in the supine normal and hypertensive human. Miniature disposable catheters ${ }^{1}$ were introduced into the brachial artery, the radial artery, a dorsal metacarpal vein, and the median cubital vein of the right or left arm. The catheters, made of moderately rigid polyvinyl plastic, varied in size from one that passed through a thin-wall 20-gauge needle to one that passed through a regular 22-gauge needle. The catheters were soaked for 24 hours in a $1: 1,000$ aqueous solution of benzalkonium chloride. After filling the catheters with heparinized saline, the needles were inserted into the vessels. With sterile technique, the catheters were passed through the needles and the needles were withdrawn, leaving the catheters in place. The catheters in the radial artery and metacarpal vein were manipu-

1 Albert E. Afford Co., Haddenfield, N. J. 
lated peripherally as far as possible, and in some instances, the tips lay in the volar arch and a dorsal digital vein of the proximal phalanx, respectively.

The catheters were attached to a single Statham resistance wire pressure transducer via a multiple stopcock arrangement that included a position for a syringe filled with heparinized saline. The arm and transducer were adjusted to the level of the right atrium. After determining that the position of the catheter tips allowed free irrigation with saline and aspiration of blood, the four pressures were sequentially recorded with a directwriting oscillograph. The method of sequential recording obviates the practical difficulties of calibrating multiple transducer-oscillograph systems. Although the transducer had a volume displacement of only $0.01 \mathrm{~mm}^{3}$ per $100 \mathrm{~mm} \mathrm{Hg}$, the narrow lumen of the catheter sometimes damped the pressure. For this reason, only mean pressures obtained electrically are reported.

The subjects were eight normal males with an average age of 37 years (range, 24 to 56) and ten male patients in the Chicago Veterans Administration Research Hospital with essential or renal hypertension and an average age of 41 years (range, 28 to 57 ). Five of the hypertensive subjects were not receiving medication at the time of the study. Medication in the remaining hypertensive subjects was as follows: phenobarbital in two; chlorothiazide in one; chlorothiazide and reserpine in one; phenobarbital, reserpine, hydralazine, and mecamylamine in one. Since none of the findings in the former five subjects was statistically different from those in the latter five subjects, the ten hypertensive subjects were treated as one group.

Effects of heart failure and respiratory tract infection with fever upon the upper extremity vascular bed. The patients were studied at an ambient temperature of $21.6 \pm$ $0.8^{\circ} \mathrm{C}$. An 18-gauge Cournand needle and a 21-gauge thin-wall needle were inserted into the brachial artery and antecubital vein, respectively, with the tips pointing upstream. A dorsal metacarpal vein was catheterized through a 21-gauge thin-wall needle as described above. Because of the presence of orthopnea in some cases, all patients were placed supine with the back elevated to a $30^{\circ}$ angle. The arm and pressure transducer were adjusted to right atrial levels, assumed to be $10 \mathrm{~cm}$ perpendicular to the skin of the back at the level of the fifth intercostal space. A 45- to 60-minute period of rest followed placement of the needles and catheter.

In some patients, radioactive iodinated human serum albumin was injected into the antecubital vein to measure plasma volume by the method of Gibson and Evans (10). After recording the pressures, upper extremity blood flow was measured by adapting the technique of Andres and his co-workers (6) to our preparation. Evans blue dye, $0.7 \pm 0.4 \mathrm{mg}$ per $\mathrm{ml}$, was infused through the Cournand needle into the brachial artery at the rate of $1 \mathrm{ml}$ per minute from a $30-\mathrm{ml}$ syringe. Venous blood, $5 \mathrm{ml}$, was withdrawn from the antecubital vein beginning at the 6th to 8th minute after the onset of infusion and placed in jars containing dried heparin or oxalate.
When serial studies were performed, the same antecubital vein was sampled in each study. At the completion of the study, the volume of the extremity to the level of the brachial artery needle was measured by water displacement.

After centrifugation, the optical density of the dyed plasma was read promptly in microcells at $620 \mathrm{~m} \mu$ with a Beckman model DU spectrophotometer. All samples were corrected for hemolysis (6) and recirculation. When plasma volume was measured, the concentration of dye in the sample due to recirculation was calculated. If the plasma volume was not determined, the concentration was measured in blood simultaneously obtained from the contralateral antecubital vein.

Plasma flow in milliliters per minute was calculated by dividing the infusion rate of the indicator, milligrams per minute, by the corrected plasma concentration of the indicator, milligrams per milliliter. This value was converted to blood flow using the venous hematocrit measured in sextuplicate by the microcapillary technique. The values obtained from two to three samples were averaged and are reported as $\mathrm{ml}$ per minute per $100 \mathrm{ml}$ tissue. Total bed and venous resistances were calculated by dividing the pressure gradients from brachial artery to antecubital vein and from small vein to antecubital vein, respectively, by the blood flow rate per $100 \mathrm{ml}$ tissue. These values were expressed as $\mathrm{mm} \mathrm{Hg}$ per $\mathrm{ml}$ per minute per $100 \mathrm{ml}$ tissue.

The subjects were 53 male patients in the Veterans Administration Research Hospital in Chicago. Each patient had one period of residence in the hospital during which a partial or complete study was conducted one or two times. Nineteen patients had the diagnosis of heart failure, established on the basis of the usual criteria and subsequently supported by one or more of the following therapeutic responses: radiologic evidence of decrease in heart size, decrease in plasma volume, decrease in venous pressure, decrease in body weight (more than 1 $\mathrm{kg}$ ), and diuresis. In 7 of the 19 patients, upper extremity blood flow was measured, along with other parameters, both in the decompensated and compensated states. These seven patients are, therefore, reported in detail. The average age of the 19 patients was 57 years (range, 30 to 79). Three patients, one studied twice (M.T.), were receiving reserpine at the times of the studies. None of the other patients was receiving drugs likely to affect the sympathetic nervous system. Ten patients with an average age of 44 years (range, 25 to 71 ) were studied in the afebrile convalescent state after an acute respiratory tract infection. Seven of these patients had also been studied while febrile and acutely ill. These seven patients are, therefore, reported in detail. An additional 24 patients with respiratory tract infections were also studied but are omitted from the present analysis because of the coexistence of heart, lung, renal, or liver disease.

Effect of position and exercise upon venous pressures in normal subjects and in patients with compensated hcart disease. By using a thin-wall 21-gauge needle, a 
TABLE I

Mean upper extremity vascular pressures in the supine normal and hypertensive human*

\begin{tabular}{|c|c|c|c|c|c|}
\hline & No. & $P_{B A}$ & $P_{S A}$ & Psv & $P_{L V}$ \\
\hline $\begin{array}{l}\text { Normotensive } \\
\text { subjects }\end{array}$ & 8 & $\begin{array}{c}m m ~ H g \\
100 \pm 4 \dagger\end{array}$ & $\begin{array}{l}m m \mathrm{Hg} \\
93 \pm 4\end{array}$ & $\begin{array}{c}m m ~ H g \\
11.9 \pm 3.0\end{array}$ & $\begin{array}{c}m m H g \\
9.5 \pm 2.6\end{array}$ \\
\hline $\begin{array}{l}\text { Hypertensive } \\
\text { subjects }\end{array}$ & 10 & $152 \pm 21$ & $146 \pm 21$ & $12.9 \pm 3.4$ & $10.7 \pm 3.4$ \\
\hline
\end{tabular}

* Abbreviations: $\mathrm{P}=$ pressure $; \mathrm{BA}=$ brachial artery $; \mathrm{SA}=$ small artery $; \mathrm{SV}=$ small vein $; \mathrm{LV}=$ large vein.

† Standard deviation.

miniature plastic catheter (o.d., $0.56 \mathrm{~mm}$ ) was inserted into a dorsal metacarpal vein as described above and advanced peripherally until the tip lay in a finger web vein or a dorsal digital vein of the proximal phalanx. A needle was inserted into a vein in or near the antecubital space and left in place. To avoid artifacts due to external pressure, the arm rested without binding on a shelf cushioned with sponge rubber. Pressures were simultaneously recorded from the catheter and needle using separate transducer-oscillograph systems. Both the arm and transducers were at right atrial level regardless of body position.

Pressures were recorded with the subject supine, sitting, and standing quietly on a treadmill. The treadmill was then run at a speed of 3 miles per hour with a $5^{\circ}$ upgrade for 10 minutes for both normal subjects and cardiac patients. Treadmill speed had to be reduced to 2 miles per hour for two of the patients. The treadmill was then stopped, and while the subject continued to stand, pressures were recorded for another 10 to $15 \mathrm{~min}$ utes. Because the arm-atrial-transducer relationship sometimes changed during the period of exercise (for example, some subjects leaned forward while running) but was always constant during quiet standing, only pressures obtained before and after exercise were considered accurate. These pressures were integrated over time with a planimeter.

The subjects were six normal males with an average age of 39 years (range, 24 to 75 ) and 12 heart disease patients, seven males and five females, with an average age of 43 years (range, 21 to 60 ) in the University of Minnesota Hospitals. Although 10 of the 12 patients had developed symptoms and signs of heart failure in the past, all were compensated at rest at the time of the study. Eight had mitral stenosis, one had aortic stenosis and insufficiency, and three had hypertensive heart disease. All had roentgenological evidence of cardiac enlargement, and nine were receiving digitalis. None was receiving other drugs likely to affect the cardiovascular system.

Effects of local cold, angiotensin, and levarterenol upon venous pressures in normal supine subjects. With the right hand and forearm lying in a rubber trough, a thinwalled 23-gauge needle was inserted, pointing peripherally, into a dorsal metacarpal vein. Thin-walled 20gauge needles were inserted, pointing centrally, into an antecubital vein and the brachial artery. The needles were attached to a single pressure transducer, and pressures were recorded with the arm and transducer at right atrial level. Temperatures of the skin surface and subcutaneous tissue near the site of the metacarpal vein needle were measured with banjo and needle thermistor probes, ${ }^{2}$ respectively.

Fresh saline solutions of angiotensin ( $1 \mu \mathrm{g}$ per $\mathrm{ml})$, levarterenol bitartrate $(1 \mu \mathrm{g}$ base per $\mathrm{ml})$, and acetylcholine chloride ( 5 to $15 \mu \mathrm{g}$ salt per $\mathrm{ml}$ ) were injected into the brachial artery. After their effects had disappeared, the trough was filled with ice water to a level that just covered the hand and entire forearm (four subjects), or the hand and lower half of the forearm were packed in ice chips (26 subjects). Pressures were measured at 1-minute intervals for at least $10 \mathrm{~min}$ utes. The ice water was replaced with warm water or the ice was removed. Pressures were then recorded at 1-minute intervals for an additional 10 to 16 minutes.

The study included four normal male members of the laboratory staff of the Veterans Administration Research Hospital, six normal male members of the laboratory staff of the University of Oklahoma Medical Center, and 30 normal patients (21 male, 9 female) from the Neurocardiology Center at the University of Oklahoma Medical Center. The average age of the subjects was 50 years (range, 23 to 81 ).

\section{Results}

Pressures in the supine normal and hypertensive human. In several subjects, pressure was recorded as the tip of a catheter was withdrawn from the volar arch to the site of entry into the radial artery in the wrist. The pressure did not change significantly over this length of artery, indicating that the position of the catheter tip is not critical. This is equally true for the position of the tip of the small vein catheter.

Table I compares mean pressures in normal and hypertensive subjects. The only difference is higher brachial and small artery pressures in the

\footnotetext{
2 Yellow Springs Instrument Co., Yellow Springs, Ohio.
} 


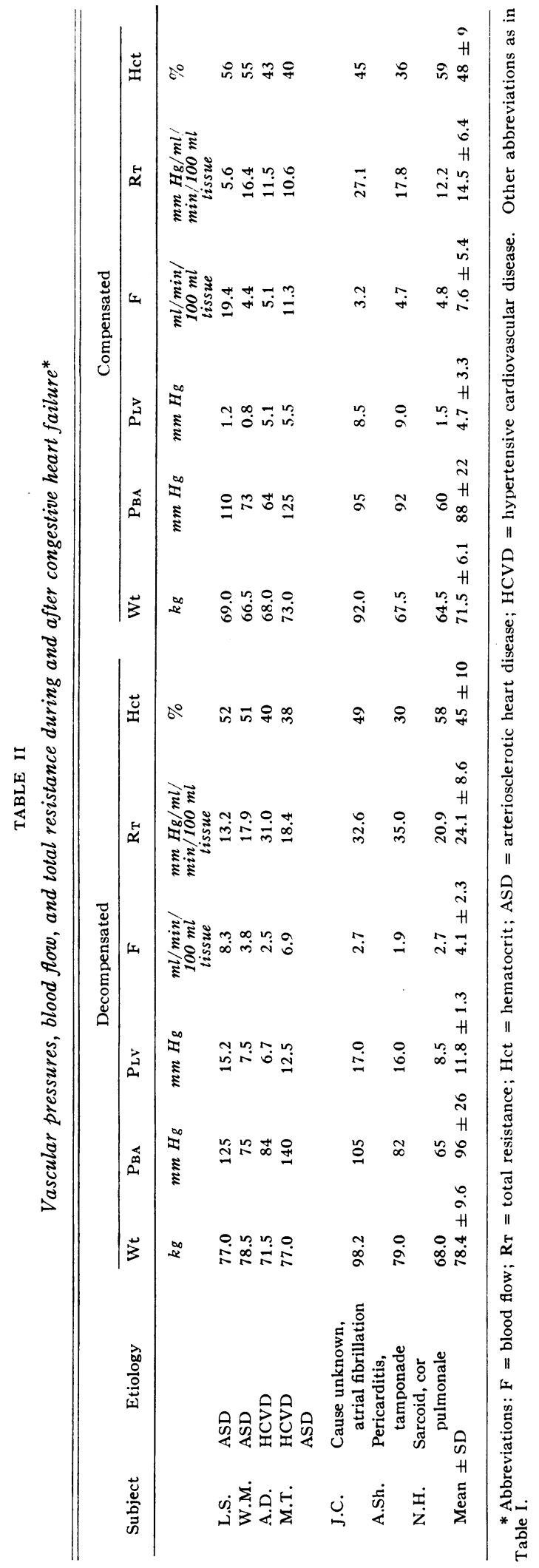

hypertensive subject. In the normotensive group, the total, arterial, small vessel, and venous pressure gradients were $90.5,7.0,81.1$, and $2.4 \mathrm{~mm}$ $\mathrm{Hg}$, respectively. Hence, of the total resistance to flow through the circuit, $89.6 \%$ was provided by the small vessels, whereas only 7.7 and $2.7 \%$ were provided by the arteries and veins, respectively.

Although there is a large variance in the mean brachial arterial pressures in the hypertensive group, there was no value so low as the highest mean brachial arterial pressure in the normotensive group. The large variance, therefore, only reflects different degrees of hypertension. In the hypertensive group, the mean total, arterial, small vessel, and venous pressure gradients were 141.3, $6.0,133.1$, and $2.2 \mathrm{~mm} \mathrm{Hg}$, repectively. In these hypertensive patients, then, the small vessels provided $94.2 \%$ of the resistance to flow through the entire circuit, whereas the arteries and veins provided only $4.2 \%$ and $1.4 \%$, respectively.

Effects of heart failure and respiratory tract infection with fever upon the upper extremity vascular bed. In each of seven patients, the measured rate of blood flow through the upper extremity was lower in the cardiac decompensated state than in the cardiac compensated state (Table II). This finding was even present in four patients who had higher pressure gradients while decompensated than while compensated. The extremity vascular resistance, therefore, was always higher in the presence of cardiac decompensation. The venous hematocrit was regularly lower in the decompensated state.

The pressures in small and large veins were higher in the decompensated state than in the compensated state (Table III). The difference in large vein pressure exceeded the difference in small vein pressure. Hence, the venous pressure gradient was lower during decompensation in each of five patients studied under both conditions. This finding was also apparent upon intergroup comparison. The mean venous pressure gradient in 13 decompensated patients (Table III) was significantly lower $(\mathrm{p}=<0.01)$ than in eight compensated patients (Table III) and lower than in any other group of patients examined in this study (Tables I, V, and VI).

The difference in flow was about in proportion 
to the difference in the venous pressure gradient. Therefore, by a paired comparison in the above mentioned five patients, the resistance to flow through veins was not significantly different in the decompensated and compensated states $(\mathrm{p}=$ $>0.6$ ). Upon progression to the compensated state, venous resistance rose in two patients but remained essentially the same in three. This finding was also apparent on intergroup comparison. Although the mean venous resistance in eight decompensated patients was slightly lower than in seven compensated patients (Table III), the difference was not statistically significant $(p=>$ 0.2 ).

In each of seven patients, the measured rate of blood flow through the extremity was higher in the presence of respiratory tract infection with fever than in the afebrile convalescent state (Table IV). This finding was even present in four patients who had lower pressure gradients while febrile than while afebrile. Extremity vascular resistance, therefore, was always lower in the presence of respiratory tract infection with fever. The venous hematocrit was usually higher in the febrile state.

Ten patients were studied in the afebrile recovered state, at a time when the chest roentgenogram was essentially clear. The average brachial arterial pressure, large vein pressure, blood flow, total resistance, and hematocrit were $83.2 \pm 12.9$ $\mathrm{mm} \mathrm{Hg}, 4.8 \pm 2.5 \mathrm{~mm} \mathrm{Hg}, 5.1 \pm 1.7 \mathrm{ml}$ per minute per $100 \mathrm{ml}$ tissue, $18.4 \pm 8.0 \mathrm{~mm} \mathrm{Hg}$ per ml per minute per $100 \mathrm{ml}$ tissue, and $37 \pm 4 \%$ (data from seven of these ten patients appear in Table IV). The value for upper extremity blood flow is comparable to the value of $4.7 \pm 2.4 \mathrm{ml}$ per minute per $100 \mathrm{ml}$ tissue reported by Andres and his co-workers (6) for normal subjects.

Venous resistance was studied in four subjects. Patient J. M. (Table IV) had a small vein pressure of $8.0 \mathrm{~mm} \mathrm{Hg}$ and a venous resistance of $0.53 \mathrm{~mm} \mathrm{Hg}$ per $\mathrm{ml}$ per minute per $100 \mathrm{ml}$ tissue while febrile. The latter value is to be compared to venous resistances of $1.13,1.23$, and $0.87 \mathrm{~mm}$ $\mathrm{Hg}$ per $\mathrm{ml}$ per minute per $100 \mathrm{ml}$ tissue in three subjects (not presented in Table IV) studied in the afebrile convalescent state.

Effects of position and exercise upon venous pressures in normal subjects and in patients with 


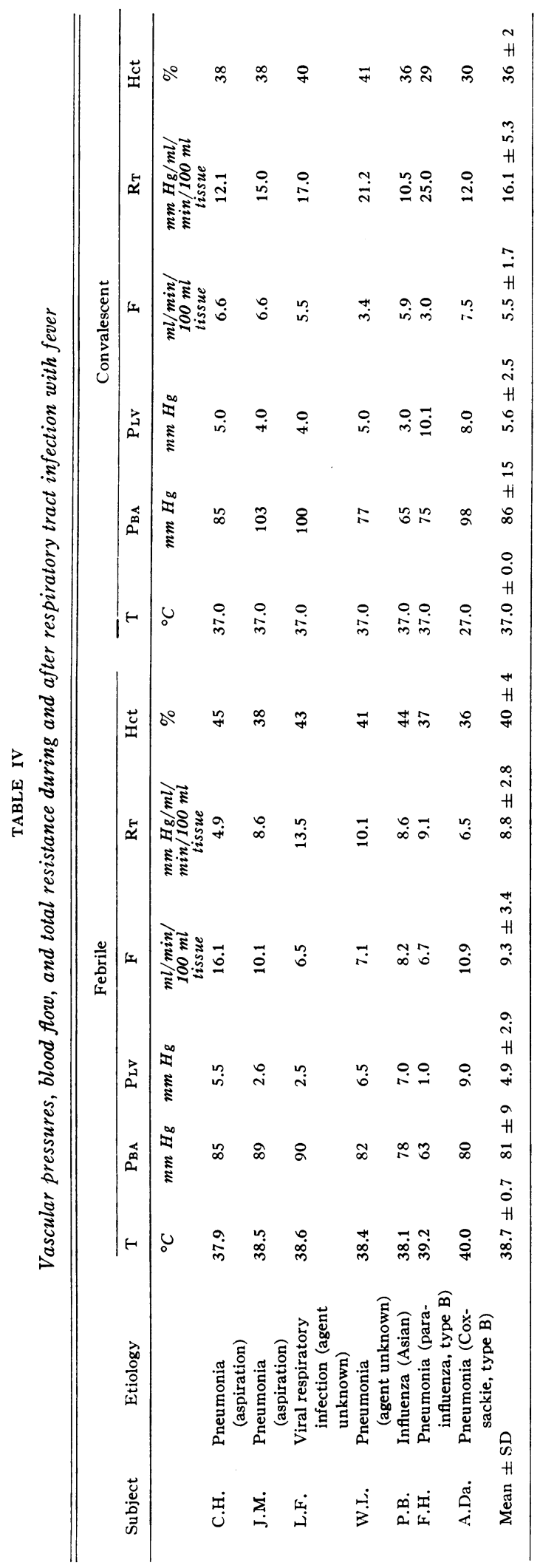

compensated heart disease. None of the resting small and large vein pressures in the patients was significantly different from those in the normal subjects (Table V). Also, within each group, change of position did not significantly alter the pressures (the higher average values in the normal subjects while sitting and standing resulted mainly from changes in only one subject). Exercise, however, elevated the pressures in both the normal subjects and in the patients. In the normal subjects, small and large vein pressures rose about equally during exercise and subsided equally during recovery. There was, therefore, no change in the small to large vein pressure gradient. In the patients, however, large vein pressure rose less than small vein pressure during exercise.

TABLE V

Average effects of position and exercise upon forearm venous pressures and venous pressure gradient $\pm S D$ in six normal subjects and twelve patients with compensated heart disease

\begin{tabular}{|c|c|c|c|c|c|c|}
\hline & \multicolumn{3}{|c|}{ Normal subjects } & \multicolumn{3}{|c|}{ Heart clisease patients } \\
\hline & Psv & $P_{L V}$ & $\Delta \mathrm{P}$ & Psv & $P_{\text {LV }}$ & $\Delta \mathrm{P}$ \\
\hline & $\stackrel{m m}{H g}$ & $\stackrel{m m}{H g}$ & $m m H g$ & $\stackrel{m m}{H g}$ & $\stackrel{m m}{H g}$ & $m m H g$ \\
\hline Supine & 12.4 & 8.4 & $4.3 \pm 2.2$ & 11.5 & 8.4 & $3.3 \pm 1.6$ \\
\hline Sitting & 14.7 & 12.4 & $3.4 \pm 2.2$ & 11.0 & 8.2 & $2.9 \pm 1.5$ \\
\hline Standing & 13.9 & 10.2 & $3.8 \pm 2.3$ & 11.6 & 7.7 & $3.9 \pm 1.7$ \\
\hline $100 *$ & 17.6 & 13.9 & $3.8 \pm 1.8$ & 16.1 & 10.1 & $6.0 \pm 3.0 \dagger$ \\
\hline 200 & 16.4 & 12.3 & $4.2 \pm 2.3$ & 15.5 & 10.0 & $5.5 \pm 2.8$ \\
\hline 300 & 15.2 & 11.9 & $3.3 \pm 2.2$ & 14.9 & 9.9 & $4.9 \pm 3.4$ \\
\hline 400 & 15.2 & 11.6 & $4.2 \pm 2.5$ & 14.2 & 9.8 & $4.4 \pm 3.5$ \\
\hline 500 & 15.1 & 12.3 & $3.4 \pm 1.7$ & 14.4 & 10.1 & $4.3 \pm 3.5$ \\
\hline
\end{tabular}

* Time in seconds after stopping treadmill.

$\dagger$ Rise from standing value significant at the $<0.01$ confidence level by $t$ test. Fall from 100 -second value significant at $<0.01$ confidence level an average of 10.7 minutes later.

This produced a significant increase in the pressure gradient immediately after exercise, which gradually disappeared during the recovery period.

Spontaneous fluctuations in pressure were more common in the small vein than in the large vein. Although these fluctuations were usually small, they were quite large in an occasional subject. For example, in one normal supine subject observed over a 15-minute period, the small vein pressure spontaneously fluctuated over a range of $7 \mathrm{~mm} \mathrm{Hg}$ while the large vein pressure varied less than $1 \mathrm{~mm} \mathrm{Hg}$. The period of the fluctuations varied from 10 to 45 seconds. The subject was quiet and apparently relaxed.

Effects of local cold, angiotensin, and levarterenol upon venous pressure in normal supine sub- 
jects. In amounts that were without effect upon brachial artery pressure, intrabrachial injection of levarterenol produced a transient fall in small vein pressure followed by a relatively sustained rise above the control value (Figure 1, Table VI). This response was observed in 15 of 15 subjects. In 12 of 13 subjects who received more than one different dose, the larger dose produced the greater rise in small vein pressure. Subcutaneous tissue temperature in the area of the small vein needle started falling shortly after the injection and remained low during the pressor phase. Large vein pressure rose slightly. In 14 of 15 subjects, the responses to angiotensin, 0.65 and $1.65 \mu \mathrm{g}$, were not different from those described for levarterenol (Figure 2, Table VI). One subject

TABLE VI

Average effects of levarterenol, angiotensin, and acetylcholine injected intrabrachially upon small and large vein pressures

\begin{tabular}{|c|c|c|c|c|c|c|c|c|}
\hline \multirow[b]{2}{*}{ Agent } & \multirow[b]{2}{*}{ Dose } & \multirow[b]{2}{*}{ No. } & \multicolumn{2}{|c|}{ Control } & \multicolumn{2}{|c|}{ Minimal* } & \multicolumn{2}{|c|}{ Maximal† } \\
\hline & & & Psv & PLv & Psv & Plv & Psv & Plv \\
\hline & $\mu g$ & & $m m$ & $H g$ & $m m$ & $\mathrm{Hg}$ & $m m$ & $H g$ \\
\hline \multirow[t]{4}{*}{ Levarterenolf } & 0.32 & 7 & 10.0 & 7.0 & 8.3 & 7.1 & 13.9 & 7.3 \\
\hline & 0.65 & 15 & 9.5 & 7.0 & 8.2 & 6.8 & 15.6 & 8.2 \\
\hline & 1.65 & 6 & 9.2 & 6.7 & 8.4 & 6.7 & 15.4 & 8.2 \\
\hline & 2.65 & 4 & 10.4 & 7.9 & 10.3 & 7.6 & 19.5 & 11.4 \\
\hline \multirow[t]{2}{*}{ Angiotensin } & 0.65 & 15 & 9.9 & 6.7 & 8.8 & 6.8 & 14.6 & 7.8 \\
\hline & 1.65 & 6 & 9.4 & 6.1 & 8.6 & 5.8 & 14.0 & 7.7 \\
\hline \multirow{2}{*}{$\begin{array}{l}\text { Acetylcholine } \\
\text { chloride }\end{array}$} & 3.25 & 5 & 10.6 & 8.1 & & & 13.3 & 10.0 \\
\hline & 8.25 & 5 & 13.4 & 9.5 & & & 16.6 & 11.6 \\
\hline
\end{tabular}

* Minimal pressure during transient depressor phase.

† Maximal pressure during prolonged pressor phase.

$\ddagger$ Dose in terms of the base.

exhibited only a fall in small vein pressure. Although not apparent in Table VI, the larger dose produced the greater rise in small vein pressure in five of six subjects given both doses. Acetylcholine increased small and large vein pressures ( $\mathrm{Ta}-$ ble VI). The elevations were maximal in about 30 seconds and were gone in about 90 seconds.

Immersion of the hand and forearm in ice water or packing the hand and lower half of the forearm in ice produced a slow large rise in small vein pressure (Figure 3 ). Small vein pulse pressure also gradually increased in some experiments. The pressure often continued to rise for several minutes after removal of the ice water or ice and then gradually returned to the control level. Large vein pressure was not regularly affected. Skin surface and subcutaneous tis-

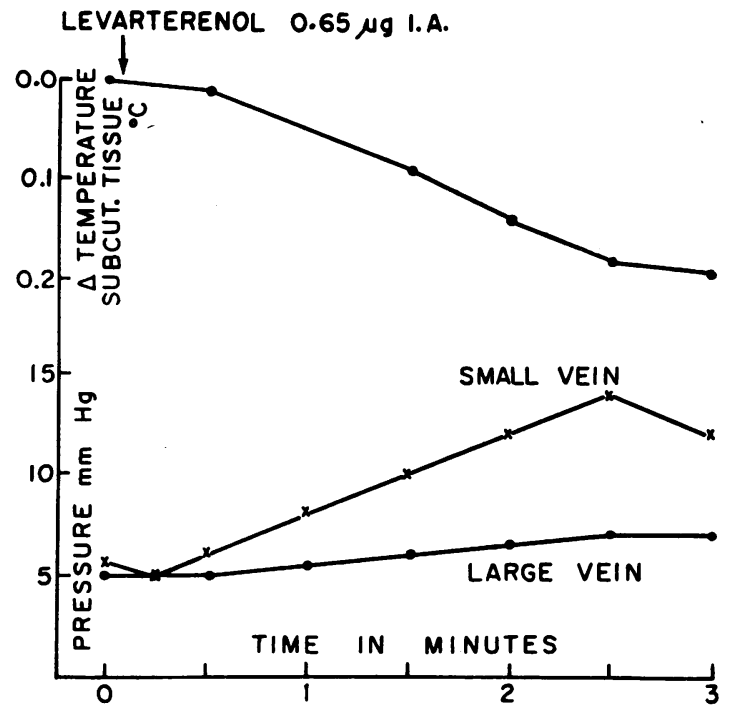

Fig. 1. EFFect of intrabrachial injection of LEVARTERENOL UPON SMALL AND LARGE VEIN PRESSURES AND SUBCUTANEOUS TISSUE TEMPERATURE IN THE AREA OF THE SMALL VEIN NEEDLE IN ONE NORMAL SUBJECT.

sue temperature fell below $20^{\circ} \mathrm{C}$ by the end of the period of cold exposure (Figures 4 and 5 ). They then gradually rose, but control levels were not achieved within ten minutes. Brachial arterial pressure exhibited the usual transient rise seen in a cold pressor test (Figure 4). All of the cooled areas were red in color by the end of the period of exposure. The erythema gradually

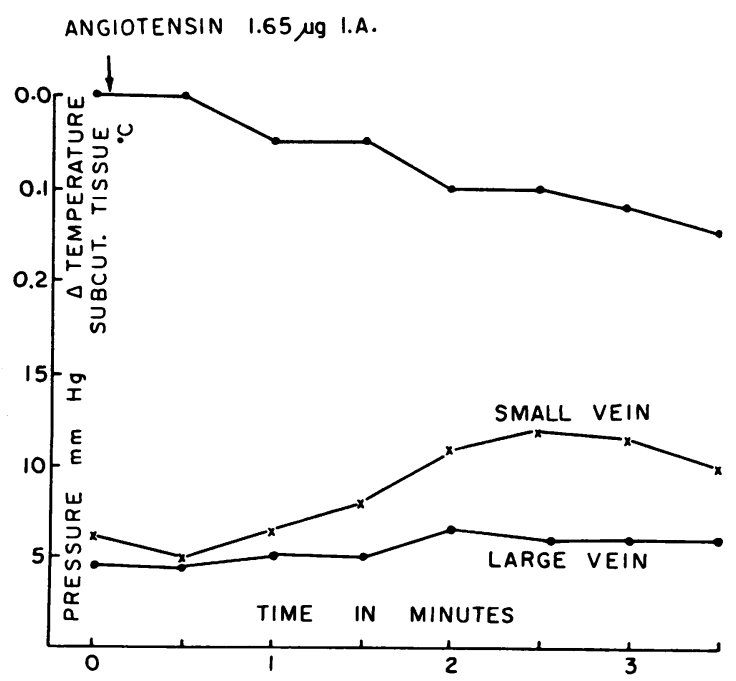

Fig. 2. EFFect OF INTRABRACHIAL INJECTION OF ANGIOTENSIN UPON SMALL AND LARGE VEIN PRESSURES AND SUBCUTANEOUS TISSUE TEMPERATURE IN THE AREA OF THE SMALL VEIN NEEDLE IN ONE NORMAL SUBJECT. 

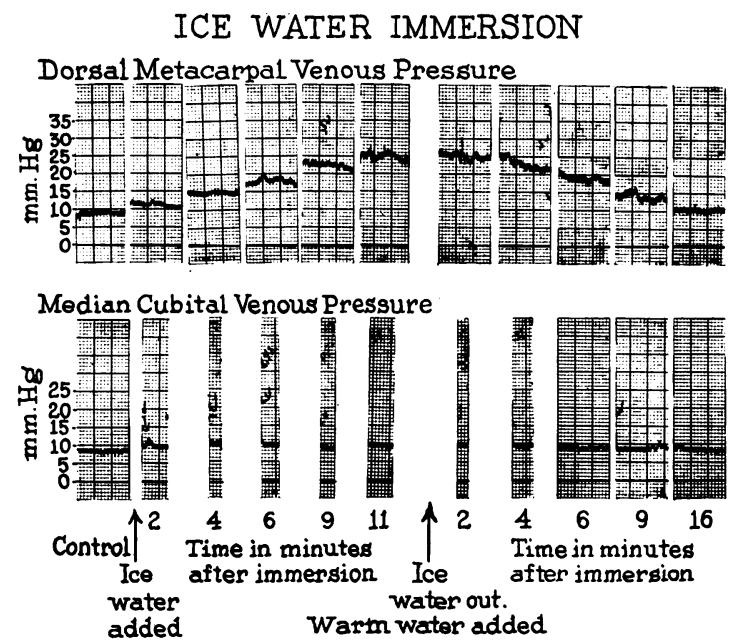

Fig. 3. EFFECT OF IMMERSION OF THE FOREARM IN ICE WATER UPON SMALL AND LARGE VEIN PRESSURES.

disappeared during the next 10 minutes. Although, on the average, small vein pressure did not rise as high in the middle age group as in the older and younger groups (Figure 5), the differences did not achieve statistical significance.
Neither was there a difference between the responses in males and females.

In two of the ice water experiments, phentolamine methanesulfonate, $5 \mathrm{mg}$, was injected into the contralateral antecubital vein when small vein pressure was well elevated. The pressure quickly fell 16 and $4 \mathrm{~mm} \mathrm{Hg}$, respectively. These pressure falls represent 67 and $44 \%$ of the elevations in pressure.

\section{Discussion}

Pressures in the supine normal and hypertensive human. This study shows that the pressure gradients down the lengths of the large arteries and large veins are practically identical in the normotensive subject and hypertensive patient. The small vessel gradient is, however, much greater in the hypertensive patient. Extremity blood flow in man with essential or renal hypertension apparently does not differ greatly from that in normotensive man (11). Therefore, these pressure studies suggest that the elevated peripheral resistance in essential and renal hypertension re-

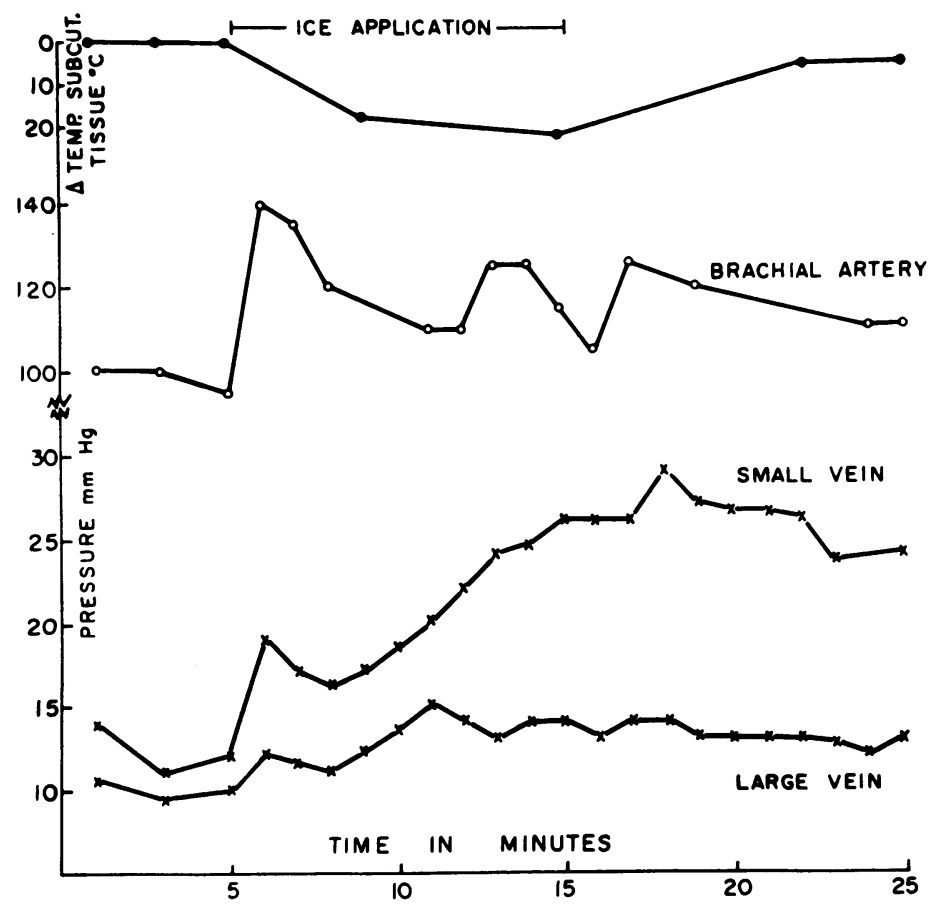

Fig. 4. EFFECT OF PACKING THE HAND AND LOWER FOREARM IN ICE UPON SMALL AND LARGE VEIN PRESSURES, BRACHIAL ARTERIAL PRESSURE, AND SUBCUTANEOUS TISSUE TEMPERATURE IN THE AREA OF THE SMALL VEIN NEEDLE IN ONE NORMAL SUBJECT. 
sults only from constriction of the small blood vessels. The failure to find a significant decrease in the brachial artery to small artery pressure gradient in the hypertensive patient despite a much higher transmural pressure suggests that the compliance of the large arteries is low. A definitive answer to this question must, however, await studies of the compliance of the large artery segment in the normal subject.

Effects of heart failure and respiratory tract infection with fever upon the upper extremity vascular bed. This study clearly shows that the rate of blood flow through the upper extremity is reduced in low output congestive heart failure. This abnormality has been previously suggested by changes in skin temperature $(12,13)$, heat loss $(14,15)$, arteriovenous oxygen or carbon dioxide difference (16-18), and by plethysmography (19$25)$. Since the pressure gradient across the extremity vascular bed was not less in the decompensated state, the reduced flow clearly results from an increase in the resistance to blood flow through the forearm. This finding indicates that the upper extremity vascular bed participates in the rise in total peripheral resistance that occurs in low output congestive heart failure (26-31). Furthermore, the rise in extremity vascular resistance apparently results from a reduction in vessel caliber rather than from an increase in blood viscosity because the venous hematocrit was lower in the congested state. The mechanism of the constriction is unknown, but animal studies suggest the participation of a baroreceptor-induced sympathicoadrenal discharge (32). These studies imply that a sudden reduction of cardiac output lowers the arterial pressure, which in turn reduces the flow through an extremity. The fall in pressure is, however, immediately sensed by the baroreceptors, which normalize arterial pressure partly by constricting the periphery. The flow through the extremity is now low because of increased resistance to flow. The peripheral constriction might also result in part from a local mechanism. Recent studies indicate that a rise in venous pressure causes arteriolar constriction ("venous-arteriolar response"), a response which tends to minimize edema formation (33). The mechanism of this local response is as yet not clearly defined.

The general site of the constriction may be de-

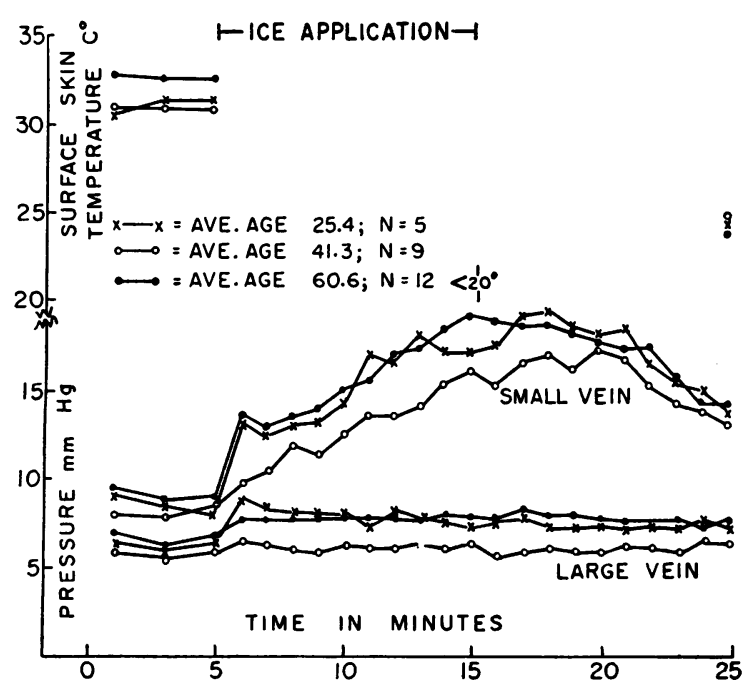

Fig. 5. Average effects of packing the hand and LOWER FOREARM IN ICE UPON SMALL AND LARGE VEIN PRESSURES AND SKIN TEMPERATURE IN THREE DIFFERENT AGE GROUPS.

duced from the data. Resistance to blood flow from the brachial artery to the small vein was elevated, whereas the resistance to flow from the small vein to the antecubital vein was normal or reduced. By inference, then, the calibers of some blood vessels upstream to the small vein were constricted, whereas the calibers of the veins between the sites of pressure measurement in the small and antecubital veins were normal or increased. Increased venous calibers, when present, most likely result from passive distention due to the elevated venous transmural pressure. Normal venous calibers despite elevated venous transmural pressure indicate a decrease in venous compliance, a change which has been demonstrated by plethysmographic techniques (22-25), and implies an increase of tension in the venous wall. The decrease in venous compliance most likely results from the same sympathicoadrenal discharge that is in part responsible for the upstream constriction.

Elevated small vein pressure was also demonstrated in the patients with low output congestive heart failure. This finding suggests that capillary hydrostatic pressure is elevated and that the edema is at least in part related to an elevated net filtration pressure.

The pressure in a small vein may rise because of an increase in small vein blood volume or a de- 
crease in small vein compliance. Small vein blood volume may increase because of an increase of flow into the small vein or because of a decrease in flow out of the small vein. Flow into the small vein may increase because of a rise in aortic pressure or decrease in upstream resistance. Flow out of the small vein may decrease because of increase of downstream resistance or increase of right atrial pressure. Low output congestive heart failure did not affect brachial arterial pressure, increased upstream resistance, did not regularly change resistance to flow between the small and large vein, but raised antecubital vein pressure. Hence, the rise in small vein pressure must have been related to the rise in antecubital vein pressure. The study, by itself, does not indicate the cause of the rise in antecubital vein pressure, since resistance to flow from the antecubital vein to the right atrium and right atrial pressure were not measured. Other investigators, however, have observed a rise in right atrial pressure and a decrease in the pressure gradient from antecubital vein to right atrium in congestive heart failure $(21,29,30)$. These observations, taken with the finding of a low extremity flow in this study, suggest that the caliber of the veins downstream to the antecubital fossa were not smaller than normal. Hence, small vein pressure apparently rises because of increase in right atrial pressure rather than from decrease in the caliber of downstream veins. The rise in small vein pressure is augmented, however, by the decrease in venous compliance.

These studies also show that the rate of upper extremity blood flow is increased in the presence of respiratory tract infection with fever. This finding is not unexpected in view of the known effects of heat upon the peripheral circulation $(34,35)$. In 1913, Stewart (36) reported low foot blood flow in a patient febrile with pneumonia. More recently, Walsh and Burch (37) reported low digital blood flow in 15 of 20 patients ill with Asian influenza and presumably febrile. These findings are as yet unexplained. Since the pressure gradient across the extremity vascular bed was not higher in the presence of respiratory tract infection with fever, the elevated flow clearly results from a decrease in resistance to flow through the extrenity. Furthermore, the fall in extremity vascular resistance apparently results from increase in vessel caliber rather than from decrease in blood viscosity because the venous hematocrit was almost always higher in the febrile state.

Effects of position and exercise upon venous pressure in normal subjects and in patients with compensated heart disease. Small vein pressure rose during exercise. This also occurs in animals $(2,38)$. Since capillary pressure cannot be lower than small vein pressure, this finding suggests that exercise increases capillary hydrostatic pressure. An increase in capillary hydrostatic pressure could explain the fall of plasma volume that occurs during exercise in healthy subjects and in patients with heart disease (39).

The mechanism of the rise in small vein pressure during exercise may differ somewhat in the normal subject and in the patient with compensated heart disease. Increase in flow is undoubtedly a factor in both. However, the small to large vein pressure gradient did not change in the group of normal subjects but increased in the patients with heart disease. Muth, Wormald, Bishop, and Donald (14) found that, in supine patients with rheumatic heart disease, the heat elimination from the hand was reduced at rest, and decreased further with leg exercise, showing only a delayed rise as exercise continued relative to normal subjects. The oxygen saturation of blood from deep veins of the forearm was unchanged during exercise in normal subjects but decreased in most patients with rheumatic heart disease. They concluded that the rise in hand flow during supine leg exercise is delayed and less pronounced in patients with heart disease. A smaller increase in upper extremity flow with a larger increase in venous pressure gradient would imply that venous calibers between the sites of pressure measurement were smaller immediately after exercise in the patients than in the normal subjects and that small vein pressure rose by the same amount in the two groups because the effect of the difference in flow was nullified by the effect of the difference in downstream venous calibers. Such a difference in venous calibers could result from a more pronounced baroreceptor-induced sympathicoadrenal discharge in the patient with compensated heart disease because of an impaired ability to increase 
cardiac output in response to exercise. While a comparison of the absolute vein pressures suggests passive vasomotion as a cause of the difference in venous calibers, such a conclusion is not warranted because the values were not statistically different. Whatever the mechanism of the difference, it rapidly disappears on rest.

Contrary to expectation, large vein pressure did not rise more in the patient with compensated heart disease than in the normal subject. This might be related to a smaller increment in flow (14) due to the heart disease and to lesser exercise (two patients could not tolerate a treadmill speed of 3 miles per hour).

Wood (40) found a decrease in forearm venous compliance on mild leg exercise in supine patients with congestive heart failure. This response was absent after administration of a sympathetic ganglioplegic agent. The same exercise was without effect in compensated patients. The amount of exercise was, however, considerably less than in the present study. Sharpey-Schafer (23) reported a decrease in venous compliance on exercise in normal subjects and in patients with heart failure. These findings are, however, difficult to interpret because there is no assurance that the starting venous volume was the same during rest and exercise.

The study also revealed that the pressures in small veins are spontaneously more labile than those in large veins. This has been previously observed in the normal unanesthetized $\operatorname{dog}(7)$ and by Wallace and Stead (41) in the normal unanesthetized human. Fluctuation in small vein pressure without equal fluctuation in large vein pressure could result from fluctuation of flow subsequent to change in aortic pressure or upstream resistance or from fluctuation in the resistance to flow through veins between the sites of pressure measurement in the small and large veins. Regardless of the mechanism, the changing pressure suggests that capillary pressure and, hence, fluid exchange across the capillary membrane are not static over time even in the resting state. Furthermore, it demonstrates that there need be no fixed correlation between small vein pressures and those in larger, more central veins. Reliance upon large vein pressure to indicate what is going on in the periphery is, therefore, not proper.
Effects of local cold, angiotensin, and levarterenol upon venous pressure in normal supine subjects. Levarterenol, injected intra-arterially in amounts without effect upon arterial pressure, raised pressure in the small vein. This response has also been observed in animals $(2,38,42,43)$ and, during prolonged intra-arterial infusion, is associated with increases in organ weight $(44,45)$ and volume (46). These findings have been interpreted to indicate a rise in capillary hydrostatic pressure and efflux of fluid from the capillary $(44,45)$. Small vein pressure also rises after intravenous injection of epinephrine in animals (38) and intravenous infusion of levarterenol in man $(41,47)$. Furthermore, Freeman, Freedman, and Miller (48) observed a fall in blood volume and a rise of hematocrit with edema and hypotension during prolonged intravenous infusion of epinephrine in dogs. Rosenthal and DiPalma (49) reported a rise of hematocrit as well as accumulation of fluid in the pericardial sac and subcutaneous tissues during the development of tolerance to the hypertensive effect of intravenously infused levarterenol in normal and splenectomized dogs. Plasma expanders caused disappearance of tolerance. They concluded that loss of circulating plasma volume seems to be a major factor in the development of tolerance to the pressor action of levarterenol in dogs. Tolerance also develops in man and hypotension occurs after stopping an infusion (50). A pheochromocytoma may decrease blood volume (51) and hypotension sometimes follows removal of pheochromocytoma (52). These findings suggest that capillary hydrostatic pressure also rises after systemic exposure to epinephrine or levarterenol, and the resulting fall in blood volume is at least in part responsible for the observed changes in blood pressure.

The mechanism of the rise in small venous pressure after intrabrachial injection of levarterenol appears to be a rise in downstream resistance out of proportion to the rise in upstream resistance. The upstream vessels are exposed to the agent first and have a shorter response time (53). Constriction of these vessels $(2,38,46,54,55)$ decreases the inflow into the small vein, causing an immediate fall in small venous pressure. Very shortly thereafter, the downstream vessels are ex- 
posed to the agent. Constriction of these vessels $(2,8,38,42-46,54,55)$ out of proportion to the upstream vessels (44-46) so impedes the outflow from the small vein that the pressure now rises above the control value. That the initial rise in pressure above the control value does not result from release of upstream constriction in the presence of less than proportionately constricted downstream vessels or simply from reactive upstream dilation is indicated by the temperature measurements and by blood flow studies in animals (2, 38 ). These factors could, however, have a role in maintaining the pressure above the control value, particularly since veins appear to relax slower than arteries (53).

In this study, intrabrachial injection of angiotensin also produced a transient fall in small vein pressure followed by a sustained rise well above the control value. However, DePasquale and Burch (47) observed no change in small vein pressure upon intrabrachial injection of either angiotensin ( 0.6 to $0.8 \mu \mathrm{g})$ or levarterenol $(0.7$ to $1.0 \mu \mathrm{g})$ in man, and intra-arterial administration of angiotensin produces no change or a fall in small vein pressure in animals $(2,8,43,45)$. Furthermore, prolonged intrabrachial infusion does not increase forelimb weight in the dog (45). Clearly, the mechanism of the rise in small vein pressure observed in this study needs further investigation. The temperature change suggests the mechanism is venous constriction as described for levarterenol. However, injection of angiotensin into an intact isolated segment of a large superficial vein in the human forearm produces little evidence of venous constriction (56), and local administration has little effect on the veins of animals $(2,8,55,57)$. On the other hand, intravenous administration produces a slight rise in the pressure within the intact presumably isolated segment of superficial forearm vein (56) and a decrease in forearm venous compliance (58).

Acetylcholine produced only a rise in small vein pressure. This has also been observed in animals (2). Hence, acetylcholine, when administered locally, may also increase capillary hydrostatic pressure and efflux of fluid from the capillary. The weight of the dog forelimb increases slightly during a prolonged intrabrachial infusion of methacholine (45). Resistance calculations in animals (2) indicate that the rise in small vein pressure results from increased inflow into the small vein subsequent to decrease in upstream resistance. The pressure rise is, however, antagonized by simultaneous slight decrease in downstream resistance (2).

The rise in small vein pressure during local cold exposure has been observed previously in man (41) and in animals $(59,60)$. However, the levels achieved in this study clearly indicate that cold exposure can raise capillary pressure in man. This is of interest because hypovolemia, hemoconcentration, edema, and hypotension are sometimes observed in cold exposure (61). Animal studies suggest that the mechanism of the rise in small vein pressure on local cold exposure is increase in downstream resistance out of proportion to increase in upstream resistance (60). Downstream resistance may increase both because of increase in blood viscosity and active venous constriction. Reduction of blood temperature from $37^{\circ} \mathrm{C}$ to $20^{\circ} \mathrm{C}$, a change similar to that seen in the subcutaneous tissue in this study, will double the viscosity of blood $(60,62,63)$. Exposure of the skin to cold may activate the sympathicoadrenal system (64), a change in keeping with the ameliorating effect of phentolamine seen in this study.

\section{Summary}

Pressures were measured at four sites along the length of the vascular bed in the human upper extremity. These sites included the brachial artery, the radial artery or one of its branches, a vein on the dorsum of the hand or proximal phalanx, and a vein in or near the antecubital space. Extremity blood flow was estimated by an indicator-dilution method.

In essential and renal hypertension, the pressure gradient from small artery to small vein was elevated. The pressure gradients from brachial artery to small artery and from small vein to antecubital vein were normal. These findings suggest that the elevated peripheral resistance results from constriction of the smaller vessels.

Congestive heart failure decreased the rate of blood flow by increasing the resistance to flow. Since the hematocrit was low, the increase in resistance results from vascular constriction. Ante- 
cubital vein pressure rose more than small vein pressure. The decrease in the venous pressure gradient was about in proportion to the decrease in flow. Venous resistance was, therefore, not elevated, suggesting that the vascular constriction is upstream to the small vein and compliance of the veins is low. Elevation of small vein pressure (and, by inference, capillary hydrostatic pressure) apparently results both from rise of right atrial pressure and decrease of venous compliance.

Respiratory tract infection with fever increased the rate of blood flow through upper extremity by decreasing the resistance to flow. Since the hematocrit was often elevated, the decrease in resistance results from vascular dilation.

Change in position did not affect venous pressure, but exercise increased small vein pressure in normal subjects and in patients with compensated heart disease. This finding suggests that the loss in plasma volume during exercise results from elevation of capillary hydrostatic pressure. In resting subjects, small vein pressure was spontaneously more variable than antecubital vein pressure.

In normal subjects, intrabrachial injection of levarterenol or angiotensin produced a transient fall in small vein pressure followed by a relatively sustained rise above the control value. Subcutaneous tissue temperature in the area of the small vein started falling shortly after injection and remained low during the pressor phase. Acetylcholine produced only a rise in pressure. Exposure of the hand or the hand and forearm to cold produced a slow large rise in small vein pressure.

\section{Acknowledgments}

We are grateful to Drs. Richard Ebert, Craig Borden, and Stewart Wolf for allowing us to study patients at the University of Minnesota Heart Hospital, Chicago Veterans Administration Research Hospital, and the University of Oklahoma Medical Center, respectively. We are also grateful for the scientific assistance of Drs. M. Visscher, M. Danford, C. Gunn, and B. Heller and for the technical assistance of Booker and Sim Swindall.

\section{References}

1. Lillehei, J. P. A Study of the Effect of Heart Disease and of Body Position on the Venous Pressure Gradient in Human. Thesis, University of Minnesota, 1954.
2. Haddy, F. J. Vasomotion in systemic arteries, small vessels and veins determined by direct resistance measurements. Minn. Med. 1958, 41, 162.

3. Overbeck, H., R. Coburn, C. Borden, and F. Haddy. Small and large vessel pressures in the upper extremity of normal and hypertensive men (abstract). Clin. Res. 1960, 8, 189.

4. Daugherty, R. M., Jr., and F. J. Haddy. The effects of levarterenol and angiotensin on small venous pressure in the human hand (abstract). Clin. Res. 1963, 11, 288.

5. Haddy, F. J. Peripheral vascular resistance. Amer. Heart J. 1960, 60, 1.

6. Andres, R., K. L. Zierler, H. M. Anderson, W. N. Stainsby, G. Cader, A. S. Ghrayyib, and J. L. Lilienthal, Jr. Measurement of blood flow and volume in the forearm of man; with notes on the theory of indicator-dilution and on production of turbulence, hemolysis, and vasodilatation by intravascular injection. J. clin. Invest. 1954 33, 482.

7. Haddy, F. J., A. G. Richards, J. L. Alden, and M. B. Visscher. Small vein and artery pressures in normal and edematous extremities of dogs under local and general anesthesia. Amer. J. Phyiol. 1954, $176,355$.

8. Haddy, F. J., J. C. Molnar, C. W. Borden, and E. C. Texter, Jr. Comparison of direct effects of angiotensin and other vasoactive agents on small and large blood vessels in several vascular beds. Circulation 1962, 25, 239.

9. Haddy, F. J. Ionic action on blood vessels. Biochem. Clinics 1963, 1, 29.

10. Gibson, J. G. II, and W. A. Evans, Jr. Clinical studies of the blood volume. I. Clinical application of a method employing the azo dye "Evans blue" and the spectrophotometer. J. clin. Invest. $1937,16,301$.

11. Fries, E. D. Hemodynamics of hypertension. Physiol. Rev. 1960, 40, 27.

12. Cohn, A. E., and J. M. Steele. Unexplained fever in heart failure. J. clin. Invest. 1934, 13, 853.

13. Stewart, H. J., W. F. Evans, H. Brown, and J. R. Gerjuoy. Peripheral blood flow, rectal and skin temperature in congestive heart failure. The effects of rapid digitalization in this state. Arch. intern. Med. 1946, 77, 643.

14. Muth, H. A. V., P. N. Wormald, J. M. Bishop, and K. W. Donald. Further studies of blood flow in the resting arm during supine leg exercise. Clin. Sci. 1958, 17, 603.

15. Stewart, G. N. Studies on the circulation in man. $X$. The blood-flow in the hands in diseases of the heart. Arch. intern. Med. 1914, 13, 1.

16. Landt, H., and J. E. Benjamin. Changes in the content of carbon dioxide in venous blood during rebreathing experiments. Comparison of change in persons with a normal heart and in patients with cardiac disease. Arch. intern. Med. 1941, 67, 72. 
17. Pearce, R. G. A possible explanation for the cyanosis and hyperpnea seen in pneumonia and cardiac decompensation. J. Lab. clin. Med. 1917, 2, 867.

18. Scott, R. W. The total carbonate content of the arterial and venous plasma in patients with chronic heart disease. Proc. Soc. exp. Biol. (N. Y.) 1919, 17, 19.

19. Abramson, D. I., S. M. Fierst, and K. Flachs. Fiffects of muscular exercise upon the peripheral circulation in patients with valvular heart disease. J. clin. Invest. 1942, 21, 747.

20. Hewlett, A. W., and J. G. Van Zwaluwenburg. The rate of blood flow in the arm. Heart 1909, 1, 87.

21. McMichael, J., and E. P. Sharpey-Schafer. The action of intravenous digoxin in man. Quart. J. Med. 1944, 13, 123.

22. Burch, G. E. A method for measuring venous tone in digital veins of intact man. Evidence for increased digital venous tone in congestive heart failure. Arch. intern. Med. 1954, 94, 724.

23. Sharpey-Schafer, E. P. Venous tone: effects of reflex changes, humoral agents and exercise. Brit. med. Bull. 1963, 19, 145.

24. Wood, J. E., J. Litter, and R. W. Wilkins. Peripheral venoconstriction in human congestive heart failure. Circulation 1956, 13, 524.

25. Sharpey-Schafer, E. P. Venous tone. Brit. med. J. 1961, 2, 1589.

26. Seymour, W. B., W. H. Pritchard, L. P. Longley, and J. M. Hayman, Jr. Cardiac output, blood and interstitial fluid volumes, total circulating serum protein, and kidney function during cardiac failure and after improvement. J. clin. Invest. 1942, 21, 229.

27. Stead, E. A., Jr., J. V. Warren, and E. S. Brannon. Effect of lanotoside $\mathrm{C}$ on the circulation of patients with congestive failure. A study using catheterization of the right side of the heart. Arch. intern. Med. 1948, 81, 282.

28. Bloomfield, R. A., B. Rapoport, J. P. Milnor, W. K. Long, J. G. Mebane, and L. B. Ellis. The effects of the cardiac glycosides upon the dynamics of the circulation in congestive heart failure. I. Ouabain. J. clin. Invest. 1948, 27, 588.

29. Richards, D. W., Jr. Dynamics of congestive heart failure. Amer. J. Med. 1949, 6, 772.

30. Eichna, L. W., S. J. Farber, A. R. Berger, D. P. Earle, B. Rader, E. Pellegrino, R. E. Albert, J. D. Alexander, H. Taube, and S. Youngwirth. The interrelationships of the cardiovascular, renal and electrolyte effects of intravenous digoxin in congestive heart failure. J. clin. Invest. 1951, 30, 1250.

31. Eichna, L. W., S. J. Farber, A. R. Berger, D. P. Earle, B. Rader, E. Pellegrino, R. E. Albert, J. D. Alexander, H. Taube, and S. Youngwirth. Cardiovascular dynamics, blood volumes, renal functions and electrolyte excretion in the same patients dur- ing congestive heart failure and after recovery of cardiac compensation. Circulation 1953, 7, 674.

32. Heymanns, C., and E. Neil. Reflexogenic Areas of the Cardiovascular System. Boston, Little, Brown, 1958 , p. 87.

33. Haddy, F. J. Local control of vascular flow in The Peripheral Blood Vessels, International Academy of Pathology Monograph, no. 4. Baltimore, Williams \& Wilkins, 1963, p. 92.

34. Shepherd, J. T. Physiology of the Circulation in Human Limbs in Health and Disease. Philadelphia, W. B. Saunders, 1963.

35. Altschule, M. D., A. S Freedberg, and M. J. McManus. Circulation and respiration during an episode of chill and fever in man. J. clin. Invest. $1945,24,878$.

36. Stewart, G. N. Studies on the circulation in man. VIII. The blood flow in the feet with special reference to fever. J. exp. Med. 1913, 18, 372.

37. Walsh, J. J., and G. E. Burch. The digital rheoplethysmogram during Asian influenza. Amer. J. med. Sci. 1960, 240, 163.

38. Haddy, F. J. Physiological Studies of the Venous System. Thesis, University of Minnesota, 1953

39. Gauer, O. H., and J. P. Henry. Circulatory basis of fluid volume control. Physiol. Rev. 1963, 43, 423.

40. Wood, J. E. The mechanism of the increased venous pressure with exercise in congestive heart failure. J. clin. Invest. 1962, 41, 2020.

41. Wallace, J. M., and E. A. Stead, Jr. Spontaneous pressure elevations in small veins and effects of norepinephrine and cold. Circulat. Res. 1957, 5, 650 .

42. Haddy, F. J., A. G. Richards, and M. B. Visscher. Pressures in small and large veins and arteries (abstract). Amer. J. Physiol. 1952, 171, 731.

43. Haddy, F. J. Effect of levarterenol upon venous pressure in the rabbit ear. Angiology 1961, 12, 486.

44. Estensen, R. D., and R. P. Gilbert. Response of ileal segment weight to prolonged levarterenol infusion. Amer. J. Physiol. 1961, 201, 628.

45. Haddy, F. J., J. I. Molnar, and R. W. Campbell. Effects of denervation and vasoactive agents on vascular pressures and weight of $\operatorname{dog}$ forelimb. Amer. J. Physiol. 1961, 201, 631.

46. Lewis, D. H., and S. Mellander. Competitive effects of systemic control and tissue metabolites on resistance and capacitance vessels and capillary filtration in skeletal muscle. Acta physiol. scand. 1962, 56, 162.

47. DePasquale, N. P., and G. E. Burch. Angiotensin II, digital blood flow, and the precapillary and postcapillary blood vessels of man. Ann. intern. Med. 1963, 58, 278.

48. Freeman, N. E., H. Freedman, and C. C. Miller. The production of shock by the prolonged con- 
tinuous injection of adrenalin in unanesthetized dogs. Amer. J. Physiol. 1941, 131, 545.

49. Rosenthal, M. E., and J. R. DiPalma. A possible mechanism of tolerance to the hypertensive effects of levarterenol (abstract). Fed. Proc. 1959, $18,440$.

50. Burn, J. H., and M. J. Rand. Fall in blood pressure after a noradrenaline infusion and its treatment by pressor agents. Brit. med. J. 1959, 1, 394.

51. Bradley, J. E., J. D. Young, Jr., and G. Lentz. Polycythemia secondary to pheochromocytoma. J. Urol. (Baltimore) 1961, 86, 1.

52. Hardy, J. D., J. L. McPhail, and W. B. Gallagher, Jr. Pheochromocytoma: shock following resection. J. Amer. med. Ass. 1962, 179, 107.

53. Davis, D. L. Small blood vessel responses to sympathetic stimulation. Amer. J. Physiol. 1963, 205, 579.

54. Haddy, F. J., M. Fleishman, and D. A. Emanuel. Effect of epinephrine, norepinephrine and serotonin upon systemic small and large vessel resistance. Circulat. Res. 1957, 5, 247.

55. Folkow, B., B. Johansson, and S. Mellander. The comparative effects of angiotensin and noradrenaline on consecutive vascular sections. Acta physiol. scand. 1961, 53, 99.

56. DePasquale, N. P., and G. E. Burch. Effects of angiotensin II on the intact forearm vein in man. Circulat. Res. 1963, 13, 239.

57. Rose, J. C., P. A. Kot, J. N. Cohn, E. D. Fries, and
G. E. Eckert. Comparison of effects of angiotensin and norepinephrine on pulmonary circulation, systemic arteries and veins, and systemic vascular capacity in the dog. Circulation 1962, 25, 247.

58. Wood, J. E. Peripheral venous and arteriolar responses to infusions of angiotensin in normal and hypertensive subjects. Circulat. Res. 1961, 9, 768.

59. Hardenbergh, E., and J. B. Roberts. Blood flow and venous pressure in the rabbit foot following freezing injury (abstract). XXI Int. Physiol. Congr., Buenos Aires, 1959, 199.

60. Scott, J. B., R. A. Hardin, and F. J. Haddy. The effect of local cooling upon small and large vessel pressures and resistances in the dog forelimb. U. S. Army med. Res. Lab. Report, no. 430, Fort Knox, Kentucky, July 21, 1960.

61. Fedor, E. J., and B. Fisher. Simultaneous determination of blood volume with $\mathrm{Cr}^{51}$ and $\mathrm{T}-1824$ during hypothermia and rewarming. Amer. J. Physiol. 1959, 196, 703.

62. Bickford, R. G., and F. R. Winton. The influence of temperature on the isolated kidney of the dog. J. Physiol. (Lond.) 1937, 89, 198.

63. Hegnauer, A. H., W. J. Shriber, and H. O. Haterius. Cardiovascular response of the dog to immersion hypothermia. Amer. J. Physiol. 1950, 161, 455.

64. Haddy, F. J., M. Fleishman, and J. B. Scott, Jr. Effect of change in air temperature upon systemic small and large vessel resistance. Circulat. Res. 1957, 5, 58. 